Portland State University

PDXScholar

Engineering and Technology Management

Faculty Publications and Presentations

$9-1-2016$

\title{
Comparative Analysis for Fuzzy Cognitive Mapping
}

Byung Sung Yoon

Portland State University

Antoine J. Jetter

Portland State University, ajetter@pdx.edu

Follow this and additional works at: https://pdxscholar.library.pdx.edu/etm_fac

Part of the Operations Research, Systems Engineering and Industrial Engineering Commons Let us know how access to this document benefits you.

\section{Citation Details}

Yoon, Byung Sung and Jetter, Antoine J., "Comparative Analysis for Fuzzy Cognitive Mapping" (2016). Engineering and Technology Management Faculty Publications and Presentations. 112.

https://pdxscholar.library.pdx.edu/etm_fac/112

This Article is brought to you for free and open access. It has been accepted for inclusion in Engineering and Technology Management Faculty Publications and Presentations by an authorized administrator of PDXScholar. Please contact us if we can make this document more accessible: pdxscholar@pdx.edu. 


\title{
Comparative Analysis for Fuzzy Cognitive Mapping
}

\author{
Byung Sung Yoon, Antonie J. Jetter \\ Dept. of Engineering and Technology Management, Maseeh College of Engineering and Computer Science, \\ Portland State University, Portland, OR - USA
}

\begin{abstract}
Fuzzy Cognitive Mapping (FCM) is a semiquantitative system modeling technique that is used in technology management to capture, synthesize and analyze expert and stakeholder knowledge for the purpose of technology assessment, product planning, and scenario studies. The resulting FCM models are generated in interviews, focus groups, or workshops and represent complex and dynamic systems as elements (so-called concepts) and cause-and-effect relationships. Researchers often compare FCM to investigate cognitive differences between individuals or groups, identify unique perspectives on a specific topic, or track changes in knowledge (i.e. learning). Using a variety of metrics, comparison studies investigate diverse characteristics of FCMs, such as structure, cognitive complexity, and similarity. To date, no consensus on metrics and their interpretation has emerged. To strengthen the scientific value of FCM as a research tool, this study systematically reviews existing metrics for content, structure, and dynamic behavior and applies them to the comparison of two FCM models. It illustrates how these three types of metrics are used for comparison and reveals limitations. In particular, content metrics are needed that are generalizable for all possible weights of causal relationships. Also, structural metrics that are suitable for directed and weighted FCMs still need to be developed.
\end{abstract}

\section{INTRODUCTION}

Since they were first introduced in 1986 by Kosko [1], fuzzy cognitive maps (FCMs) have gained popularity in technology management [2] and other fields [3], [4] as a means to study individual and organizational perceptions on various topics, including product planning, future scenarios, and technology assessment [2], [5]-[8]

Fuzzy cognitive mapping is known as a useful technique to document and analyze human knowledge in a visual way and in every-day language: they represent complex and dynamic systems as "concepts" (i.e. system elements that are verbally described and do not have to be dimensionally defined, such as "technology readiness" or "customer preference") - and cause-and-effect relationships between concepts (i.e. positive or negative connections with verbally assigned weights, such as "strong" or "weak"). The visual and qualitative nature of FCM makes it possible to acquire knowledge from individuals and groups with relative ease through various approaches, including interviews, text analysis from documents, mapping exercises, and group sessions [9]. Also, FCMs can draw upon the knowledge of multiple people and groups because individual maps can be combined and expanded without restriction. Lastly, in distinction to typical cognitive maps or cause maps [10], [11], which are static, FCMs are semi-quantitative networks that can be computationally assessed to show the dynamic behavior of systems, such as the change of a concept in response to an input change [2]. Because of these advantages, research that applies FCMs as a research methodology has rapidly increased in the last decade [3] and various methodological improvements have been suggested [4], [12], [13].

In comparative analysis, diverse characteristics of FCMs, such as structure, cognitive complexity and similarity, are frequently analyzed to compare individuals or groups, identify unique perspectives on a specific topic, or track changes in knowledge (i.e. learning) as they occur over time or as a result of interventions, such as improved communication between stakeholders. In order to strengthen the scientific value of FCMs as a research tool, several methods or metrics have been proposed for comparing them [12], [14], [15]. However, there is no consensus between researchers and practitioners as to what metric to use and how to interpret the results. The objective of this paper is to aid the development of standard practices by answering the following research questions:

- What are the objectives in the comparative analysis of FCMs?

- Which kinds of metrics or criteria can be applied to comparing FCMs?

- What does each measure and criterion mean in the comparative analysis of FCMs?

- Which metrics and criteria are appropriate for the different objectives of map comparison?

To answer these questions, this study first provides a brief introduction to FCM and subsequently reviews the literature on the comparison of cognitive maps, resulting in a classification of comparison metrics according to the objective of the comparison: content comparison, structural comparison, and behavioral comparison. Each class of metrics is presented in detail and illustrated with a case example.

\section{FUZZY COGNITIVE MAPS}

The predecessors of FCM are so-called causal cognitive maps (CMs), which are used to capture causal knowledge of individuals or groups in visual structures that show concepts and their causal links [16], similar to the map in Figure 1. In this example, concept A causes concepts $\mathrm{B}$ and $\mathrm{C}$ to increase (positive arrows), while concept $\mathrm{C}$ causes concept $\mathrm{B}$ to increase and concept $\mathrm{D}$ to decrease (negative arrow). CMs have been used widely in political, sociological, and management research [10], [13], [16]-[21] but have practical 
limitations: because they are fundamentally qualitative in nature, it is difficult to analyze large maps with complex relationships and nearly impossible to draw inferences about the dynamic behaviour of the represented system. For example, simply by looking at Figure 1, it is impossible to say if an increase in concept A will cause concept $D$ to increase or decrease: the path through concept $\mathrm{C}$ suggests a decrease, while the direct path though concept $\mathrm{B}$ and the indirect path from $\mathrm{C}$ to $\mathrm{B}$ suggest an increase. Moreover, there is a feedback relationship between $\mathrm{C}$, which - as it increases - decreases A.

FCM was proposed as a means to improve the practicality of CM by adopting neural network theory [1], [22] to make dynamic inferences possible.

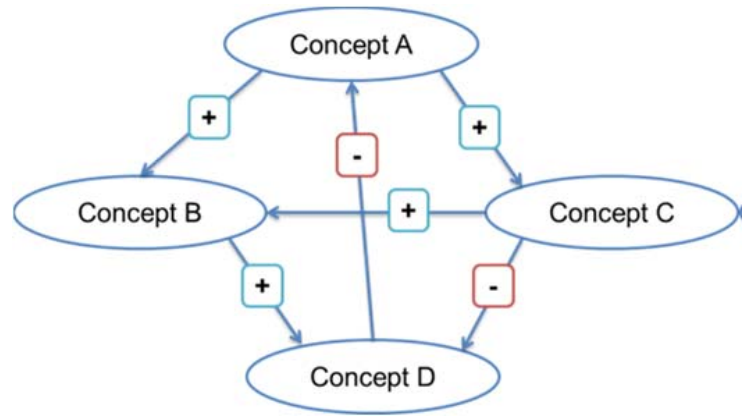

Figure 1. A simple FCM

A first step is to represent the FCM with its corresponding adjacency matrix that shows the structure of the FCM model. The matrix for the network above is presented below:

$$
\mathrm{E}=\left[\begin{array}{cccc}
0 & +1 & +1 & 0 \\
0 & 0 & 0 & +1 \\
0 & +1 & 0 & -1 \\
-1 & 0 & 0 & 0
\end{array}\right]
$$

In order to investigate the change of each concept caused by a specific decision or a scenario, a state vector which has one row and $n$ (the number of concepts) columns is multiplied by the adjacency matrix. For instance, if the concept A is only activated while others are turned off in Figure 1, the initial state vector is like below;

$$
S_{0}^{T}=\left[\begin{array}{llll}
1 & 0 & 0 & 0
\end{array}\right]
$$

This vector is multiplied with the adjacency matrix in equation (1), which leads to a new output vector. This output vector is multiplied with the adjacency matrix again and again, until the system settles down and input and output vectors are identical.

However, in neural networks, not all stimuli (input vectors) are strong enough to activate other concept (i.e. change other concepts' output value). In neural network theory, and also in FCM, this is modelled with squashing functions (or thresholds). There are several types of squashing functions such as binary, linear, sigmoid and hyperbolic tangent functions:
- Binary function:

$$
f(x)=\left\{\begin{array}{rr}
-1 & \text { for } x<0 \\
0 & \text { for } x=0 \\
1 & \text { for } x>0
\end{array}\right.
$$

- Linear function:

$$
f(x)=\left\{\begin{aligned}
-1 & \text { for } x \leq-1 \\
x & \text { for }-1<x<1 \\
1 & \text { for } x \geq 1
\end{aligned}\right.
$$

- Sigmoid function: $f(x)=\frac{1}{1+e^{-\lambda x}}$

- Hyperbolic tangent function: $f(x)=\tanh \lambda x=\frac{e^{\lambda x}-e^{-\lambda x}}{e^{\lambda x}+e^{-\lambda x}}$

where $\lambda$ adjusts the saturation level of a concept activation. A squashing function converts the multiplied values of the adjacency matrix and a former state vector to new state vector like below;

$$
S_{t}=f\left(E \cdot S_{t-1}\right)
$$

where $t$ is a certain instant of iterations. The iteration of this process continues until that the state vector reaches stable status or a stop criterion. Finally, the last state and the behaviour of each element in the state vector can be interpreted according to the objective of analysis. For example, the FCM can be used to analyze the impact of a decision (e.g. to increase A in Figure 1) on other concepts of interest.

In many FCM studies, the structure of the system under study is initially poorly understood. To build the FCM model, modellers extract information from texts (published research, expert interviews) or create the model in collaboration with individuals or groups who have system knowledge. In studies of this nature, it often useful to compare different FCM models. For example the researchers may want to compare a stakeholder groups' view of the system (represented in a stakeholder FCM) to the understanding in scientific publications or that of other stakeholders. They may also want to compare the group FCM before an intervention (e.g. a training, an information exchange, a meeting with other groups) to an FCM that was generated after the intervention in order to track how worldviews change. Over the years, such comparative analyzes have been pursued with different objectives and a variety of methods, as Figure 2 illustrates. The figure includes work on the comparison of CM, social networks, and FCM, which all rely on graph theory as the foundation [4], [10], [11], [13]-[15], [17]-[21], [23]-[29]: $\mathrm{CM}$, the predecessors of FCM are undirected or directed graphs that show the relationship between concepts. FCM are weighted and directed network graphs that can be reflexive, meaning that nodes can be related to themselves. Social networks are typically represented as undirected graphs to show the relationship between people, though directed graphs are also used in order to analyze communication flows between people [30]. 


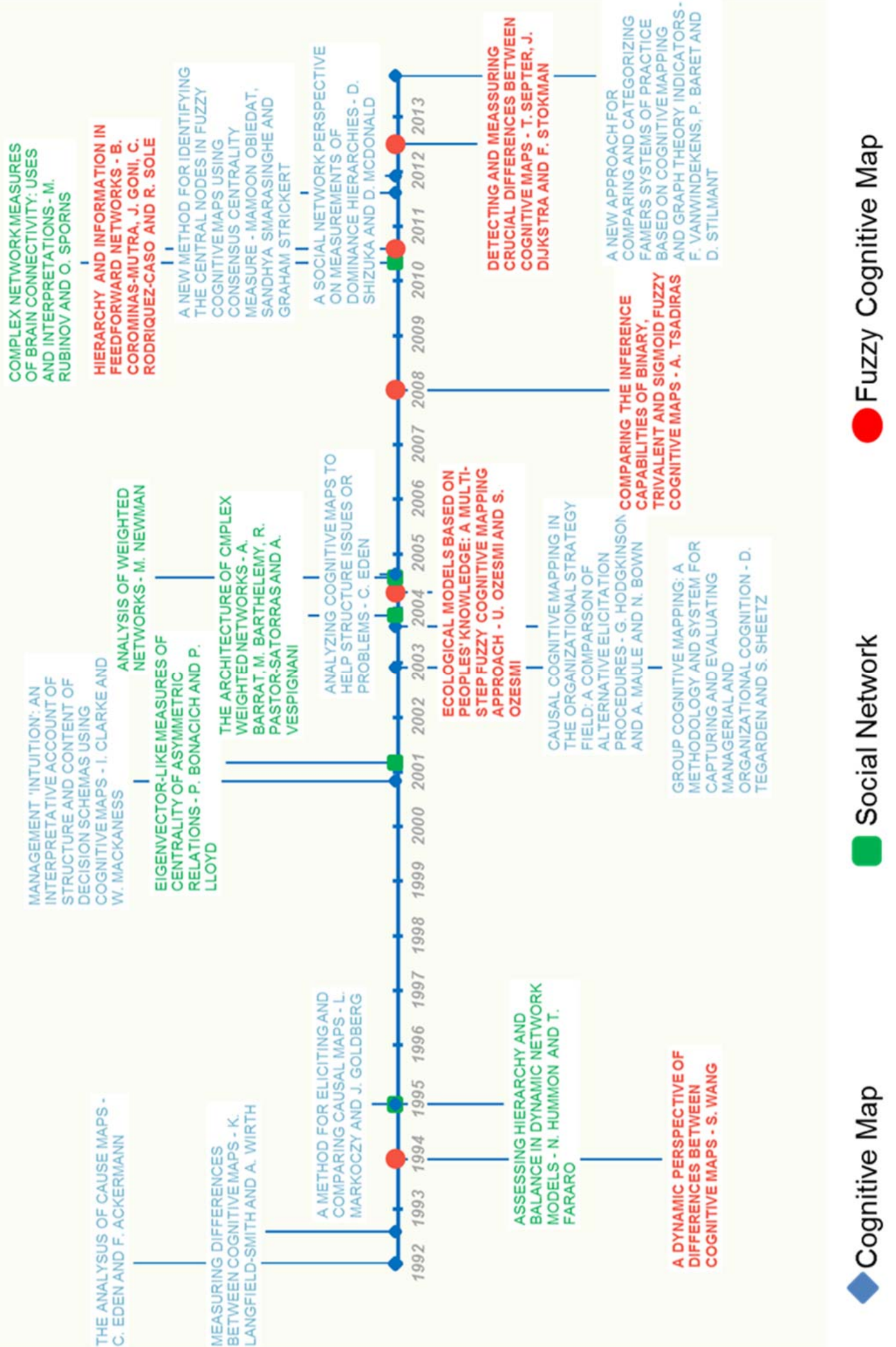

Figure 2. Timeline of Map Comparison Related Works. Title and authors of each paper are corresponded to published year. Blue, green and red coloured titles and authors indicates CM, SNA and FCM related papers correspondingly. 


\section{OBJECTIVES OF COMPARATIVE ANALYSIS}

While all the work in Figure 2 is interested in network graphs, it emphasizes different aspects. The comparative content analysis of $\mathrm{CMs}$, which dates back to the introduction of CM by Axelrod [16], is concerned with the meaning of the concepts that are included in the network. For instance, Clarke and Mackaness [18] compare two causal cognitive maps by categorizing common, partially common and uncommon concepts between the maps in order to explore individual decision-making schemas. Eden concentrates on understanding and evaluating cognitive differences of CMs by adopting the concept of cluster [11], which shows concepts that are tightly linked because they represent a particular aspect of the bigger topic under investigation. Content comparison frequently also aims to quantify similarities or differences of contents between multiple CMs [17], [21].

A large body of research is focused at the structural analysis of CM, FCM, and social networks. It aims to characterize overall network structures and to identify concepts of particular interest in the network. Commonly used metrics for network comparison are density, degree of centrality and link-node ratio (C/N Ratio) [1], [12], [19], [20], [29]. These metrics can be interpreted as indices for the cognitive complexity of maps. FCM are also analyzed with a subset of approaches from social network analysis that are suitable for weighted and directed maps, such as betweenness centrality or closeness centrality. These analyzes aim to identify concepts that strongly influence the entire perspective of each map [15], [31].

Lastly, the distinctive characteristics of FCMs as semiquantitative networks are analyzed as they relate to dynamic behaviors. To this end, FCM models are used to run simulations and to observe the resulting dynamic behavior. Wang, for example, suggests to measure dynamic differences, such as initial inputs and time horizon, between cognitive maps in order to analyze the cognitive differences between the management groups [14]. Initial inputs correspond to options of specific decisions or particular scenarios of the target FCM [4], [14]. The transient responses resulting from a specific initial inputs can be interpreted as short-term effects, while the final states can be analyzed as long-term effects [14]. The number of iterations it takes until the system settles down into a steady state (or a stop criterion is met) gives insights into time horizons. The dynamic behaviors of maps in response to a squashing function may also reveal differences in perspective between individuals or groups [4]. Taken together, the number of iterations, the patterns of "short-term" transient and "long-term" final states, and the response to changes in inputs and squashing functions reflect system characteristics that are compared across different FCM.

Table 1 summarizes the three focus areas of FCM comparison - content, structure, and dynamic behaviors - and characterizes the main objectives and metrics within each category. The metrics will be explained in the following sections.

TABLE 1. OBJECTIVES OF MAIN METRICS FOR MAP COMPARISON

\begin{tabular}{|c|c|c|c|}
\hline $\begin{array}{l}\text { Comparison } \\
\text { Types }\end{array}$ & Metrics & Objectives & References \\
\hline \multirow{3}{*}{ Content } & Cluster & $\begin{array}{l}\text { - To identify the themes that describe each } \\
\text { cluster }\end{array}$ & $\begin{array}{l}\text { Eden \& Ackermann, 1992; Eden, 2004; } \\
\text { Vanwindekens, Baret \& Stilmant, } 2014\end{array}$ \\
\hline & Distance Ratio & - To quantify content difference between maps & $\begin{array}{l}\text { Langfield-Smith \& Wirth, 1992; } \\
\text { Markoczy \& Goldberg, } 1995\end{array}$ \\
\hline & $\begin{array}{c}\text { Presence/Absence } \\
\text { Concepts }\end{array}$ & $\begin{array}{l}\text { - To identify which concepts are common, } \\
\text { partially common, or idiosyncratic }\end{array}$ & Clarke \& Mackaness, 2001 \\
\hline \multirow{5}{*}{ Structure } & Link-Node Ratio & \multirow{2}{*}{$\begin{array}{l}\text { - To determine how connected or sparse the } \\
\text { maps are }\end{array}$} & \multirow{3}{*}{$\begin{array}{c}\text { Özesmi \& Özesmi, 2004; } \\
\text { Vanwindekens, Baret \& Stilmant, } 2014\end{array}$} \\
\hline & Density & & \\
\hline & Degree of Centrality & $\begin{array}{l}\text { - To determine how connected a concept is to } \\
\text { other concepts }\end{array}$ & \\
\hline & Betweenness Centrality & \multirow{2}{*}{$\begin{array}{l}\text { - To extract which concepts influence strongly } \\
\text { to the entire perspective of each map }\end{array}$} & Obiedat et al., 2011 \\
\hline & Closeness Centrality & & Obiedat et al., 2011; Mago et al., 2013 \\
\hline \multirow{3}{*}{$\begin{array}{l}\text { Dynamic } \\
\text { Behaviors }\end{array}$} & Ultimate Concept States & $\begin{array}{l}\text { - To identify the long-term effects of scenario } \\
\text { or decision options }\end{array}$ & \multirow{3}{*}{ Wang, 1994; Tsadiras, 2008} \\
\hline & $\begin{array}{l}\text { Transient Changes of } \\
\text { Concept States }\end{array}$ & $\begin{array}{l}\text { - To identify the short-term effects of scenario } \\
\text { or decision options }\end{array}$ & \\
\hline & Number of Iterations & $\begin{array}{l}\text { - To determine the timing to differentiate } \\
\text { between short-term and long-term effects }\end{array}$ & \\
\hline
\end{tabular}




\section{Proceedings of PICMET '16: Technology Management for Social Innovation}

\section{METRICS FOR CONTENT COMPARISON}

To compare the contents of maps, four main metrics, such as cluster, distance ratio, and concept presence/absence, have been applied from CM approach to FCM one. This section explains details of these four metrics focusing on how to work for comparative analysis and how to interpret the differences of maps revealed by the metrics.

\section{A. Cluster}

Generally, FCMs consist of multiple concepts and causal relationships between them. Though each concept has distinctive meaning, some concepts may form a thematic cluster. In other words, a FCM can be divided into several clusters in which concepts are highly interconnected to each other under common themes. Also, other specific concepts can be connected less to other themes, so that these concepts seem like 'islands' [10], [11]. Technically, several computation techniques to cluster concepts of large and complex maps have been proposed and applied for various CM, SNA and FCM researches. For example, according to the recent research of Vanwindekens et al. [29], computing the dissimilarity matrix derived by the relationship presence of maps are applied for classifying individual relationships.

With clustering concepts, the number of clusters in a map can be compared with others. It means that, if maps have different number of clusters with each other, cognitive differences may exist between maps. On the contrast, if maps have same number of clusters, even though the numbers of concepts are different, the maps may have similar cognitive contents. Taking a step forward, the cognitive difference can be detected by investigating which clusters are included or not included in each map, similar with investigating presence/absence of concepts.

\section{B. Distance Ratio}

Quantification of the content difference between maps is useful to show the difference. Langfield-Smith and Wirth [21] calculated the content difference between two maps which may have different sizes using the direction of each relationship, the numbers of common concepts in both maps, and the number of unique concepts in each maps compared. Below equation is the distance ratio $(D R)$ proposed by Langfield-Smith and Wirth;

$D R(A, B)=\frac{\sum_{i=1}^{p} \Sigma_{j=1}^{p} \mid \operatorname{sgn}\left(a_{i j}\right)-\operatorname{sgn}\left(b_{i j} \mid\right.}{2 p c^{2}+2 p c\left(p u_{A}+p u_{B}\right)+p u_{A}^{2}+p u_{B}^{2}-\left(2 p c+p u_{A}+p u_{B}\right)}$

where $p$ is the number of concepts in the union of the sets of concepts in two maps compared, $A$ and $B$ are the adjacency matrices of each maps, and $a_{i j}$ (or $b_{i j}$ ) is the value of the $i$ th row $j$ th column in of $A$ (or $B$ ). $\operatorname{sgn}\left(a_{i j}\right)$ is the sign function which extracts the sign of $a_{i j} . p c$ is the number of common concepts in both maps, $p u_{A}$ (or $p u_{B}$ ) is the number of unique concepts in matrix $A$ (or $B$ ). While the numerator of above equation, so-called the matrix distance, means the difference of the contents between maps, the denominator means the maximum distance score applied for converting the matrix distance to a comparable value. $D R$ can have a value between 0 and 1 . If $D R$ is 0 , the two maps have identical contents. On the contrast, if $D R$ is 1 , then the two maps have totally different contents.

\section{Concept Difference}

Extracting common, partially common and unique concepts is a useful indicator to investigate the cognitive differences between individuals or groups and to indicate the degree of similarity and dissimilarity between maps on a research topic. For this approach, the concepts in each map are blind-coded by the researchers against a list of constructs: Constructs that appear in all cognitive maps under comparison are common concepts. Constructs that are shared between some maps but not all, are partially common constructs, and constructs that are specific to only one map are so-called individual constructs. This type of analysis enables researchers to discover cognitive commonalities or differences and draw conclusion about decision making behavior. For instance, in the research of Clarke and Mackaness about managerial intuition [18], the concepts drawn from the CMs of three different levels of managers show that managers do not differ much with regard to the shared common concepts, but that lower level and less experienced managers have a larger number of individual concepts. These concepts reflect local knowledge but, in many cases, are not relevant for effective decision making in the "bigger picture" [18].

\section{METRICS FOR STRUCTURE COMPARISON}

As mentioned above, FCMs are one type of weighted and directed graphs, which consists of concepts (or nodes) and relationships (or links) which have direction and weight. Map structure, such as density, complexity, and hierarchy, can be analyzed through a variety of quantitative measure that use nodes and links. These measures are frequently used in social network analysis. Özesmi and Özesmi [12] organize them to examine the structure of FCMs. Table 2 shows the main metrics, mathematical expressions and the interpretations for structural analysis. With these metrics, it is possible to determine how densely or sparsely concepts are connected, which concepts have strong or weak impacts on the system under study and how complex the system is in the view of the study participants. 
TABLE 2. MAIN METRICS FOR STRUCTURAL ANALYSIS (NEWLY EDITED BASED ON [32])

\begin{tabular}{|c|c|c|c|c|}
\hline Metrics & Numerical Exp & ession & Definition & References \\
\hline $\begin{array}{l}\text { Number of Concepts } \\
\text { (Nodes) }\end{array}$ & $N$ & & $\begin{array}{l}\text { Total number of identical ideas having } \\
\text { cause-effect relationships each other in a } \\
\text { map }\end{array}$ & \\
\hline Outdegree & $O d_{i}=\sum_{k=1}^{N}\left|a_{i k}\right|$ & (9) & $\begin{array}{l}\text { The cumulative strength of connections } \\
\text { with which a concept influences other } \\
\text { concepts }\end{array}$ & {$[1],[33]$} \\
\hline Indegree & $I d_{i}=\sum_{k=1}^{N}\left|a_{k i}\right|$ & (10) & $\begin{array}{l}\text { The cumulative strength of connections } \\
\text { through a concept is affected by other } \\
\text { concepts }\end{array}$ & [1], [33] \\
\hline Transmitter & $T\left(O d_{i} \neq 0 \wedge I d_{i}=0\right)$ & & $\begin{array}{l}\text { A concept which only influences other } \\
\text { concepts (Forcing variables or Tails) }\end{array}$ & {$[10]$} \\
\hline Receiver & $R\left(O d_{i}=0 \wedge I d_{i} \neq 0\right)$ & & $\begin{array}{l}\text { A concept which is only affected by } \\
\text { other concepts (Utility variables or } \\
\text { Heads) }\end{array}$ & {$[10]$} \\
\hline Ordinary & $O\left(O d_{i} \neq 0 \wedge I d_{i} \neq 0\right)$ & & $\begin{array}{l}\text { A concept which is affected by and also } \\
\text { influences other concepts }\end{array}$ & {$[12]$} \\
\hline $\begin{array}{l}\text { Number of } \\
\text { Relationships (Links) }\end{array}$ & $C$ & & $\begin{array}{l}\text { Total number of connections linking } \\
\text { each concepts in a map }\end{array}$ & \\
\hline Density & $D=\frac{C}{N(N-1)} \vee D=\frac{C}{N^{2}}$ & (11) & $\begin{array}{l}\text { A connectivity index which show how } \\
\text { dense or spare concepts are connected }\end{array}$ & {$[12]$} \\
\hline Degree of Centrality & $c_{i}=O d_{i}+I d_{i}$ & (12) & $\begin{array}{l}\text { The degree how linked a concept to } \\
\text { other concept and the cumulative } \\
\text { strength of connections the concept has }\end{array}$ & {$[22]$} \\
\hline $\begin{array}{l}\text { Relationship-Concept } \\
\text { Ratio } \\
\text { (Link-Node Ratio, } \\
\text { Connectedness) } \\
\end{array}$ & $C / N$ & (13) & $\begin{array}{l}\text { The degree of connectivity between } \\
\text { concepts; Higher ratio indicates the } \\
\text { connection between concepts are denser }\end{array}$ & \\
\hline $\begin{array}{l}\text { Receiver-transmitter } \\
\text { Ratio (Complexity) }\end{array}$ & $R / T$ & (14) & $\begin{array}{l}\text { The degree of complexity or resolution; } \\
\text { higher ratio indicates more complex } \\
\text { cause-effect relationships in a map }\end{array}$ & {$[10]$} \\
\hline
\end{tabular}

In addition to the metrics described in Table 2, betweenness and closeness centralities are commonly applied in network analysis to identify influential nodes: Betweenness centrality is a metric for how much a concept controls interaction between other concepts; while closeness centrality measures how fast a concept deliver impacts to other concepts. Some FCM-related research includes these metrics for measuring influence of concepts [15], [31].

\section{METRICS FOR DYNAMIC BEHAVIORS}

Concept changes in FCMs (i.e. the increase or decrease of a concept's state value) trigger changes to causally connected concepts until the initial change impulse has made its way through the system and a new stable end point is reached. To calculate the end state, an input state vector is multiplied with the adjacency matrix and inputted into a squashing function. The resulting output vector is again multiplied with the adjacency matrix and "squashed" until input and output vector are equal, iterate in a fixed cycle, or a stop criterion (typically the maximum number of iterations) is met. To analyze this dynamic behavior in FCM, three metrics can be used, namely the transient response shape (a measure of the "in between" concept states before a new point of stability is reached), the ultimate states of concepts when the termination criteria are reached, and the number of iterations elapsed from the beginning of calculation to the ultimate states. These dynamic response behaviors are dependent on the structure of cause-effect system, initial inputs, and squashing functions applied for interaction between concepts.

The transient response shape shows the path of state change of a concept until reaching the termination criteria, namely a fixed point, limit cycle or a cut-off for number of iterations. It gives insights into changes that occur in the short-term. For example, when a new policy for stimulating dissemination of electric vehicles is rolled-out, a short-term responses to the policy could be an increase in purchase intention. By monitoring the short-term response in the system (i.e. Does purchase intention go up?), policy makers can anticipate if their long-term goal can be reached (i.e. more electric vehicles on the road). They may also see how the final state will be eventually reached, if, for example purchase intentions hit an early high peak as people are excited about the new technology but then level off. This insight helps decision makers set expectations: rather than adjusting sales forecasts upwards (and building capacity) at the early peak of purchase intentions, they prepare for actual future sales. The ultimate states of concepts indicate the final states resulting from an input scenario, thus showing the long-term response of the cognitive systems. If the final results of two maps show similar states of concepts after calculated with the same initial state inputs and squashing 
functions, the maps show, for the long-term perspective, a similar cause-effect system. If they lead to different results, there are systemic differences between the two maps. By looking at the degree of differences in final concept states, it is possible to understand which concepts are influenced by differences in cognitive models and to what extent.

Lastly, the number of iterations of each calculation can also be used for comparative analysis to understand differences in timing. For instance, if two maps developed by two groups of stakeholders for electric vehicles, the two groups may differ in when they reach their highest purchase intention, indicating that the two groups may belong to different segments that require different marketing strategies.

\section{ILLUSTRATION: COMPARING COGNITIVE MAPS}

The abovementioned metrics for comparative analysis of FCM are subsequently applied and discussed for two sample CMs that were initially published by Langfield-Smith and Wirth [14]. In the original work, three managers were interviewed to capture their perspectives on the success of a launch of a new alcoholic product as three separate CMs, two of which will be used for this illustration. In the original paper, these CMs have weights on the relationships in the set of $\{-3,-2,-1,1,2,3\}$. In this paper, weights are converted to $\{-1,-0.66,-0.33,0.33,0.66,1\}$ because FCM require weights in the interval $[-1 ; 1]$.

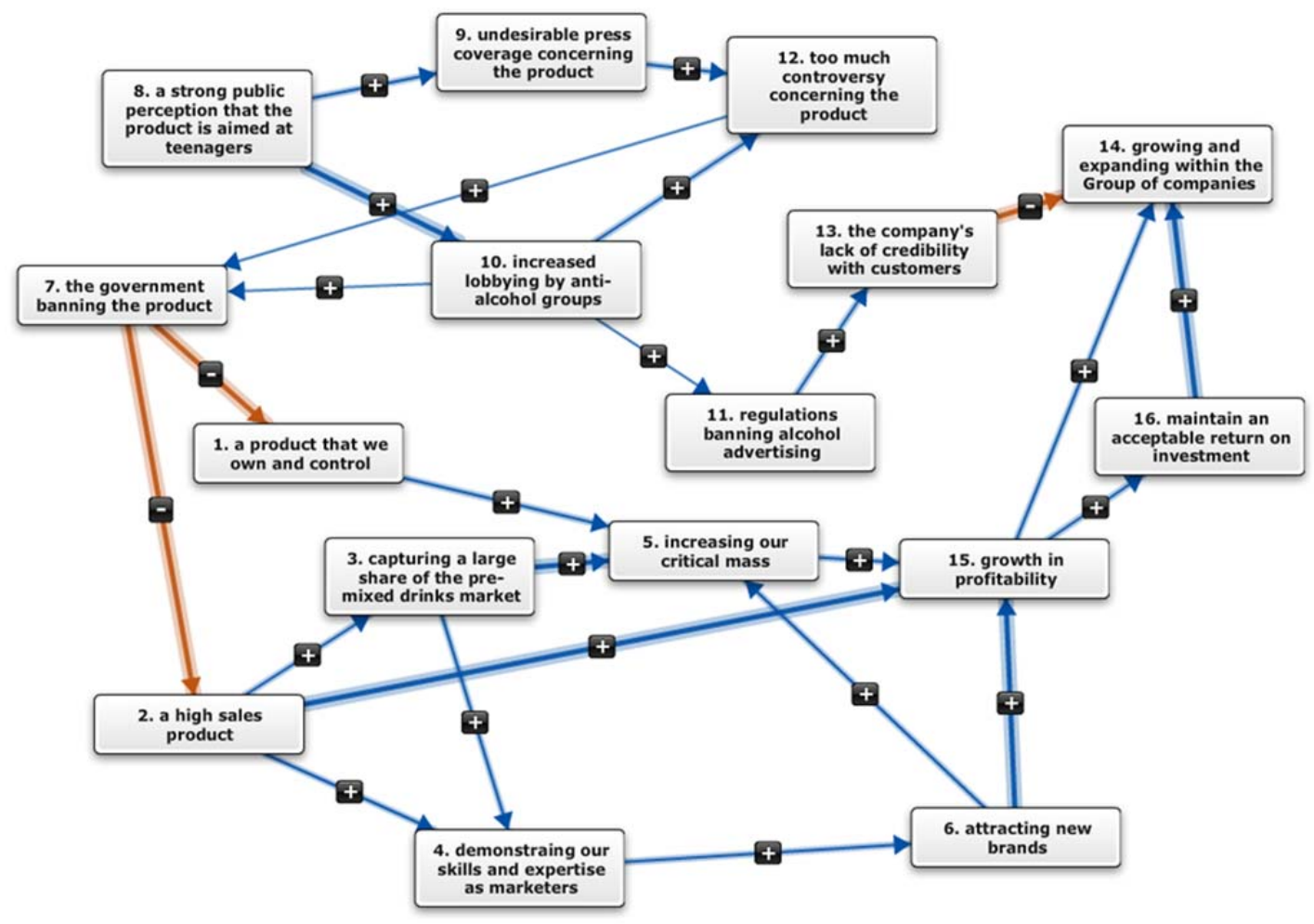

Figure 3. FCM 1 - A Fuzzy Cognitive Map developed by Manager X about launching a new alcoholic product

\begin{tabular}{|r|r|r|r|r|r|r|r|r|r|r|r|r|r|r|r|r|}
\hline & 1 & 2 & 3 & 4 & 5 & 6 & 7 & 8 & 9 & 10 & 11 & 12 & 13 & 14 & 15 & 16 \\
\hline 1 & 0 & 0 & 0 & 0 & 0.66 & 0 & 0 & 0 & 0 & 0 & 0 & 0 & 0 & 0 & 0 & 0 \\
\hline 2 & 0 & 0 & 0.66 & 0.66 & 0 & 0 & 0 & 0 & 0 & 0 & 0 & 0 & 0 & 0 & 1 & 0 \\
\hline 3 & 0 & 0 & 0 & 0.66 & 1 & 0 & 0 & 0 & 0 & 0 & 0 & 0 & 0 & 0 & 0 & 0 \\
\hline 4 & 0 & 0 & 0 & 0 & 0 & 0.66 & 0 & 0 & 0 & 0 & 0 & 0 & 0 & 0 & 0 & 0 \\
\hline 5 & 0 & 0 & 0 & 0 & 0 & 0 & 0 & 0 & 0 & 0 & 0 & 0 & 0 & 0 & 0.66 & 0 \\
\hline 6 & 0 & 0 & 0 & 0 & 0.66 & 0 & 0 & 0 & 0 & 0 & 0 & 0 & 0 & 0 & 1 & 0 \\
\hline 7 & -1 & -1 & 0 & 0 & 0 & 0 & 0 & 0 & 0 & 0 & 0 & 0 & 0 & 0 & 0 & 0 \\
\hline 8 & 0 & 0 & 0 & 0 & 0 & 0 & 0 & 0 & 0.66 & 1 & 0 & 0 & 0 & 0 & 0 & 0 \\
\hline 9 & 0 & 0 & 0 & 0 & 0 & 0 & 0 & 0 & 0 & 0 & 0 & 0.66 & 0 & 0 & 0 & 0 \\
\hline 10 & 0 & 0 & 0 & 0 & 0 & 0 & 0.33 & 0 & 0 & 0 & 0.33 & 0.66 & 0 & 0 & 0 & 0 \\
\hline 11 & 0 & 0 & 0 & 0 & 0 & 0 & 0 & 0 & 0 & 0 & 0 & 0 & -0.66 & 0 & 0 & 0 \\
\hline 12 & 0 & 0 & 0 & 0 & 0 & 0 & 0.33 & 0 & 0 & 0 & 0 & 0 & 0 & 0 & 0 & 0 \\
\hline 13 & 0 & 0 & 0 & 0 & 0 & 0 & 0 & 0 & 0 & 0 & 0 & 0 & 0 & -1 & 0 & 0 \\
\hline 14 & 0 & 0 & 0 & 0 & 0 & 0 & 0 & 0 & 0 & 0 & 0 & 0 & 0 & 0 & 0 & 0 \\
\hline 15 & 0 & 0 & 0 & 0 & 0 & 0 & 0 & 0 & 0 & 0 & 0 & 0 & 0 & 0.66 & 0 & 0.66 \\
\hline 16 & 0 & 0 & 0 & 0 & 0 & 0 & 0 & 0 & 0 & 0 & 0 & 0 & 0 & 1 & 0 & 0 \\
\hline
\end{tabular}

Figure 4. The Adjacency Matrix of the FCM 1 depicted in Figure 3 


\section{Proceedings of PICMET '16: Technology Management for Social Innovation}

Figure 3 shows the CM drawn by a manager (Manager X) as an FCM. The arrows represent relationships between concepts. A weight on a relationship is presented by the thickness of an arrow line. The weight of thickest arrows is 1 or -1 while the one of thinnest arrows is 0.33 or -0.33 . The weight of medium arrows is 0.66 or -0.66 . The '+' or '-' sign on each arrow indicates whether the relationship is positive or negative. For example, the concept number 10, 'increased lobbying by anti-alcohol groups,' impact positively and weakly $(0.33$ of weight $)$ to the concept number 11 , 'regulations banning alcohol advertising.' On the contrast, the concept number 2, 'a high sales product,' is influenced negatively and strongly by the concept number 7 , 'the government banning the product.'

Figure 4 is the adjacency matrix of FCM 1. The FCM of a second managers (Manager $\mathrm{Y}$ ) and the adjacency matrix of FCM 2 are presented in Figure 5 and Figure 6.

The comparison results of both FCMs are presented on Table 3. FCM 1 consists of sixteen concepts and twenty four relationships, while FCM 2 is comprised of fifteen concepts and twenty one relationships. The densities of both FCMs are same, the $\mathrm{C} / \mathrm{N}$ values, the ratio of relationship to concept, are similar. This means the two FCMs have similar degree of connectivity.

Both FCMs share eleven common concepts indicated grey colored rows in Table 3. The FCM 1 has five unique concepts, such as 'a high sales product,' 'the government banning the product,' 'a strong public perception that the product is aimed at teenagers,' 'regulations banning alcohol advertising' and 'the company's lack of credibility with customers,' which are not included in FCM 2. On the other hand, four unique concepts, such as 'withdrawing the product from the market,' 'increased enthusiasm of our staff,' 'further new product development' and 'allowing us to plan better,' are contained in only the FCM 2. Twenty concepts are included in the union of the two maps. These numbers, of common, of unique and of union concepts are used for calculating the distance ratio (DR) between both FCMs. The DR value is 0.049 , which means the contents of both maps are very similar with each other. For the detailed explanation of this calculation, please refer to Appendix I.

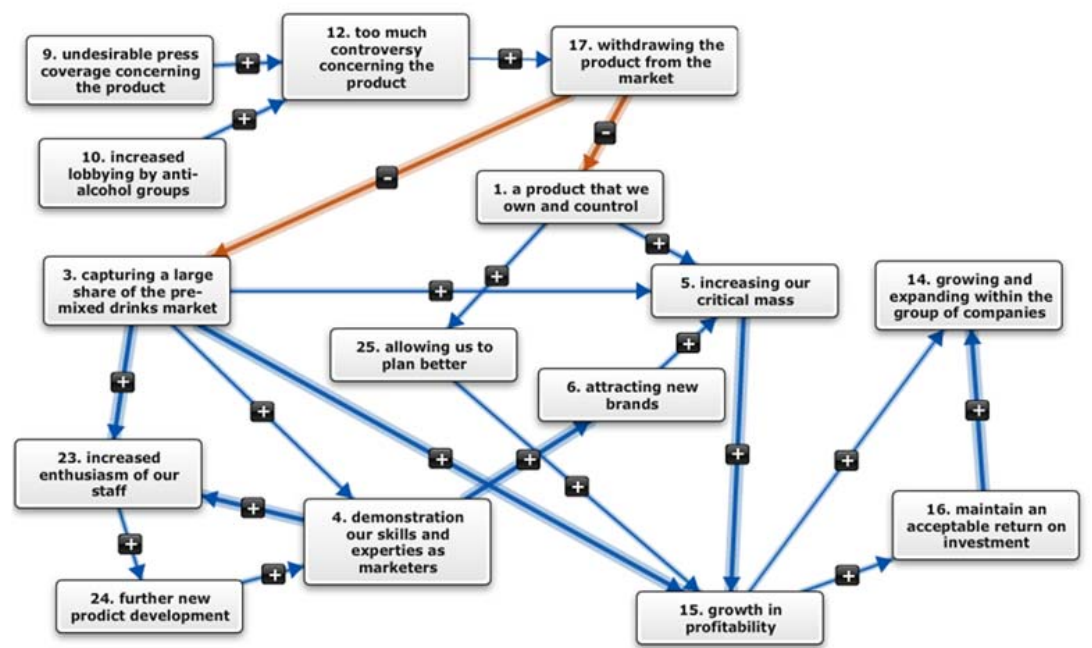

Figure 5. FCM 2 - A Fuzzy Cognitive Map developed by Manager Y about launching a new alcoholic product

\begin{tabular}{|r|r|r|r|r|r|r|r|r|r|r|r|r|r|r|r|}
\hline & 1 & 3 & 4 & 5 & 6 & 9 & 10 & 12 & 14 & 15 & 16 & 17 & 23 & 24 & 25 \\
\hline 1 & 0 & 0 & 0 & 0.66 & 0 & 0 & 0 & 0 & 0 & 0 & 0 & 0 & 0 & 0 & 0.66 \\
\hline 3 & 0 & 0 & 0.66 & 0.66 & 0 & 0 & 0 & 0 & 0 & 1 & 0 & 0 & 1 & 0 & 0 \\
\hline 4 & 0 & 0 & 0 & 0 & 1 & 0 & 0 & 0 & 0 & 0 & 0 & 0 & 1 & 0 & 0 \\
\hline 5 & 0 & 0 & 0 & 0 & 0 & 0 & 0 & 0 & 0 & 1 & 0 & 0 & 0 & 0 & 0 \\
\hline 6 & 0 & 0 & 0 & 0.66 & 0 & 0 & 0 & 0 & 0 & 0 & 0 & 0 & 0 & 0 & 0 \\
\hline 9 & 0 & 0 & 0 & 0 & 0 & 0 & 0 & 0.66 & 0 & 0 & 0 & 0 & 0 & 0 & 0 \\
\hline 10 & 0 & 0 & 0 & 0 & 0 & 0 & 0 & 0.66 & 0 & 0 & 0 & 0 & 0 & 0 & 0 \\
\hline 12 & 0 & 0 & 0 & 0 & 0 & 0 & 0 & 0 & 0 & 0 & 0 & 0.33 & 0 & 0 & 0 \\
\hline 14 & 0 & 0 & 0 & 0 & 0 & 0 & 0 & 0 & 0 & 0 & 0 & 0 & 0 & 0 & 0 \\
\hline 15 & 0 & 0 & 0 & 0 & 0 & 0 & 0 & 0 & 0.66 & 0 & 0.66 & 0 & 0 & 0 & 0 \\
\hline 16 & 0 & 0 & 0 & 0 & 0 & 0 & 0 & 0 & 1 & 0 & 0 & 0 & 0 & 0 & 0 \\
\hline 17 & -1 & -1 & 0 & 0 & 0 & 0 & 0 & 0 & 0 & 0 & 0 & 0 & 0 & 0 & 0 \\
\hline 23 & 0 & 0 & 0 & 0 & 0 & 0 & 0 & 0 & 0 & 0 & 0 & 0 & 0 & 0.66 & 0 \\
\hline 24 & 0 & 0 & 0.66 & 0 & 0 & 0 & 0 & 0 & 0 & 0 & 0 & 0 & 0 & 0 & 0 \\
\hline 25 & 0 & 0 & 0 & 0 & 0 & 0 & 0 & 0 & 0 & 0.66 & 0 & 0 & 0 & 0 & 0 \\
\hline
\end{tabular}

Figure 6. The Adjacency Matrix of the FCM 2 depicted in Figure 5. 


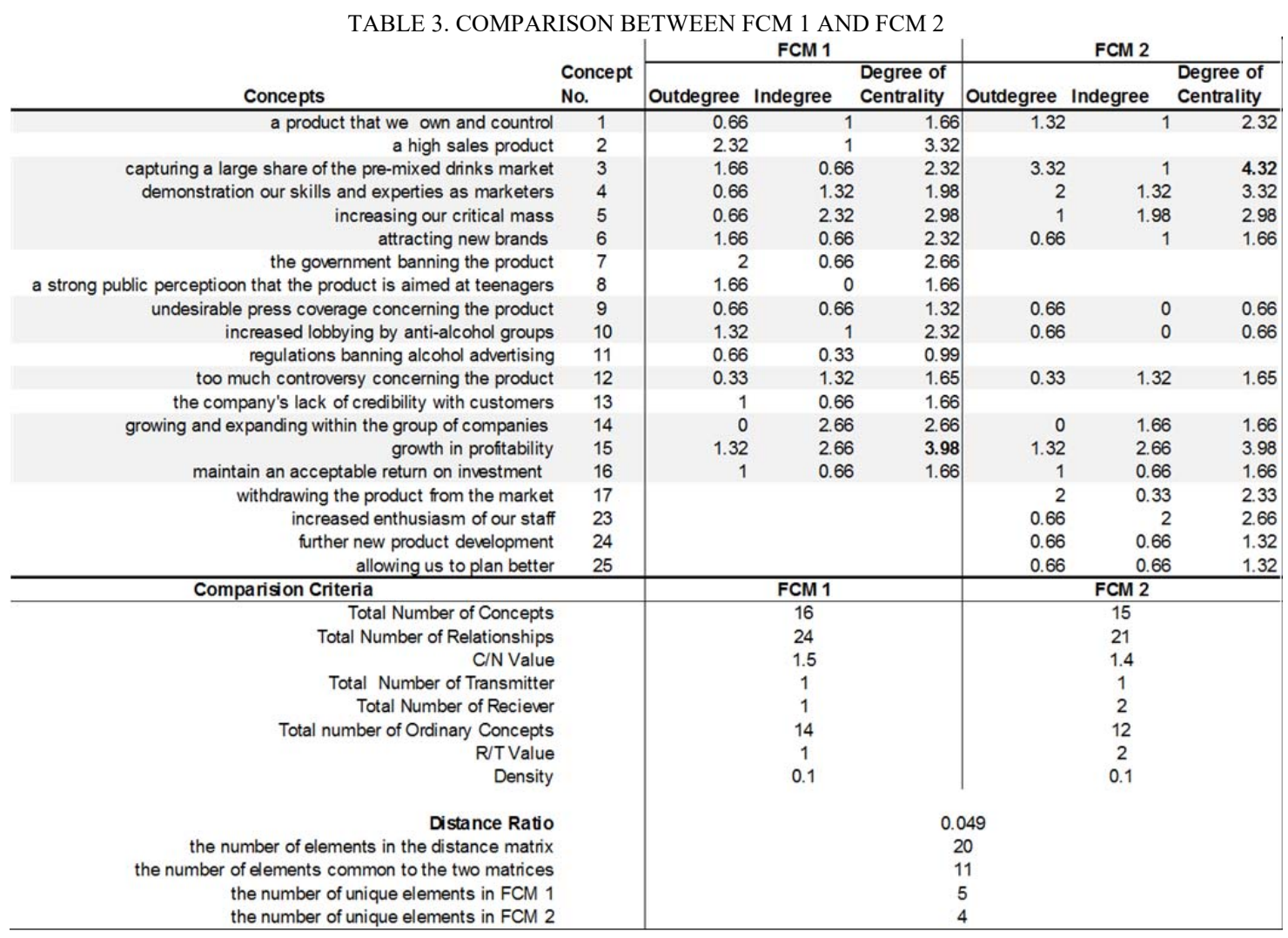

In terms of complexities of both FCMs, FCM 1 has just one transmitter and one receiver whereas FCM2 has two transmitters and one receiver. In particular, the concept, 'growing and expanding within the group of companies,' is the common receiver of both FCMs. As a result, the R/T value, the ratio of receiver to transmitter, of FCM 2 is twice than one of FCM 1, which means that FCM 2 contains more complex cognition structure than FCM1.

In FCM1, with the viewpoint of comparing the outdegree of each concept in both maps, the concept, 'a high sales product' affects most strongly its three neighboring concepts, namely 'capturing a large share of the pre-mixed drinks market,' 'demonstration our skills and expertise as marketers' and 'growth in profitability.' On the other hand, four concepts, 'demonstration our skills and expertise as marketers,' 'increasing our critical mass,' 'growth in profitability' and 'increase enthusiasm of our staff,' are influenced most strongly by the concept, 'capturing a large share of the pre-mixed drinks market' in FCM 2.

In comparing the indegree of each concept, the concept, 'growing in profitability' has the highest indegree (2.66) in both maps, but, in FCM 1, the concept, 'growing and expanding within the group of companies,' also has the same indegree value. As a result, considering the relationships between these two concepts in both FCMs, 'growing in profitability' concept is an important prerequisite for reaching 'growing and expanding within the group of companies' concept.
Observing the degree of centrality of each concept in both maps, 'growing in profitability' concept has highest value in FCM 1, whereas 'capturing a large share of the pre-mixed drinks market' concept is the most important in FCM 2. This shows the existence of cognitive difference about the success of the launch of a new alcoholic product between both managers.

In order to analyze the dynamic behaviors of both maps, three concepts that are found in both maps are investigated, namely 'undesirable press coverage concerning the product,' 'increased lobbying by anti-alcohol groups' (as inputs) and 'growing and expanding within the group of companies,' (as an output of interest and receiver variable in both FCMs). The three concepts are investigated to simulate the managers' perceptions about the impact of external factors beyond the control of the company. Accordingly, 'undesirable press coverage concerning the product' and 'increased lobbying by anti-alcohol groups,' are activated concepts in the initial (input) state vector. The scenario is simulated under the assumption that both external factors are one-time occurrences at the beginning of simulation, meaning that negative press coverage or lobbying does not continue and that, accordingly, the concepts do not have to "clamped' in the model [1]. As a squashing function, the hyperbolic tangent function with coefficient is 2 (SEE Equation (6) ABOVE) is applied for the simulation. The dynamic behavior of "growing and expanding within the groups of companies" is observed through all iterations until all concepts reach a stable state or a limit cycles occurs [34]. 


\section{Proceedings of PICMET '16: Technology Management for Social Innovation}

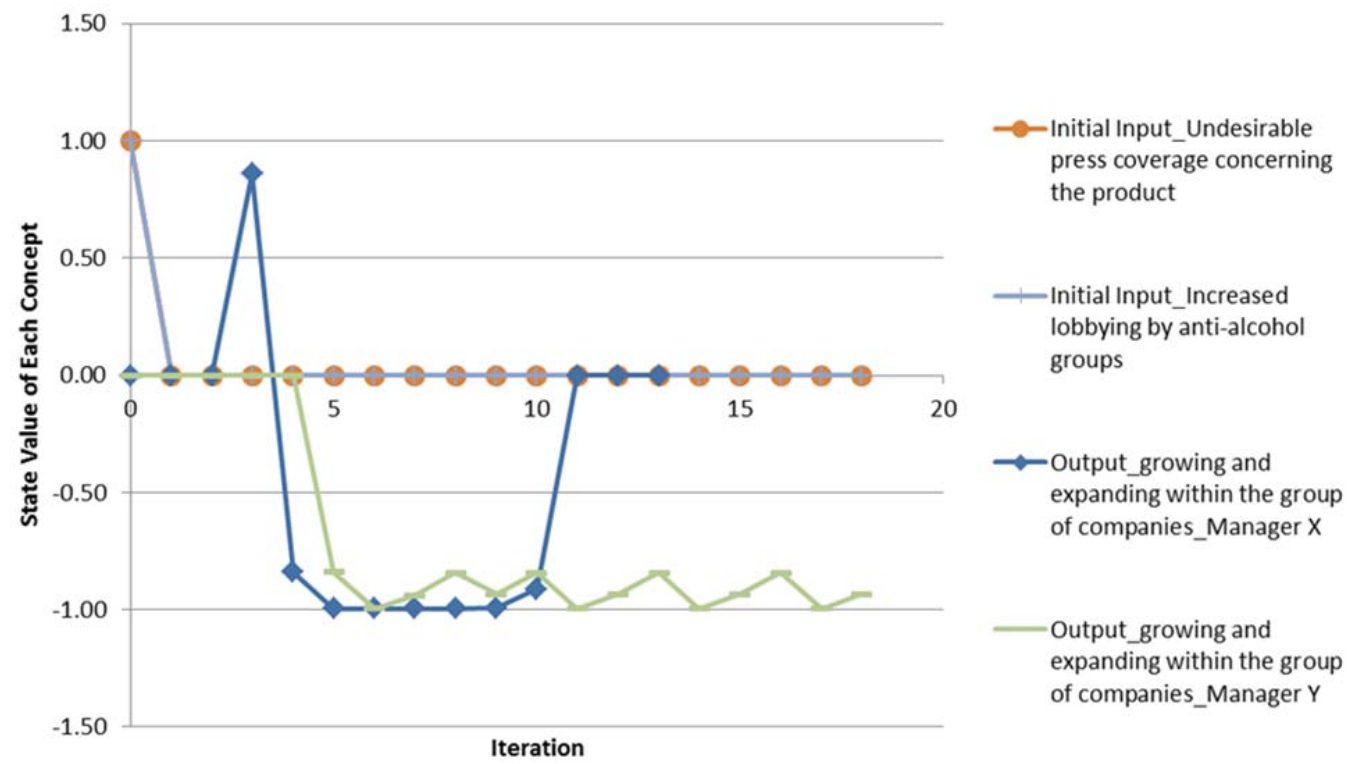

Figure 7. Dynamic behaviours of main concepts caused by the developed scenario

Figure 7 shows the simulation result. The activated concepts of the initial input are changed to zero after the first iteration but continue to impact the system until after the second iteration in FCM 1 and the fourth iteration in FCM 2 because they cause other concepts to change. The response of the receiver concept in FCM 1 returns to its original state, zero, from the eleventh iteration onward. In addition, the concept responds positively at the third iteration, but shows the negative response from the fourth to the tenth iteration. In contrast, "growing and expanding" in FCM 2 responds negatively to the impact of the two external factors and oscillates continuously between -0.84 and -0.99 . The differences between both responses can be interpreted as follows: Manager X (FCM 1) perceives the impact of the external factors to be initially negative but eventually irrelevant, whereas Manager Y understand the external factors of negative press and lobbying to continue to negatively influence the growth of the business. Given the differences in cognitive models, it is likely that the managers would chose different courses of action. While Manager X may choose to ignore negative press and lobbying, Manager $\mathrm{Y}$ is likely to attempt countermeasures.

\section{VARIATIONS AND LIMITATIONS OF EXISTING COMPARISON METRICS}

The illustration above shows the process of applying content, structure, and dynamic behavior metrics for comparison of FCM. However, as an illustration, it does not attempt to cover all possible metrics and therefore has some limitations.

The analysis of content did not use clustering techniques because the FCM are similar and strongly centered around a shared central theme, as the small distance ratio shows. The content analysis also used a relatively simple approach: In analyzing content difference between two maps, this research uses one of equations Langfield-Smith and Wirth (L\&W) suggested, which was developed for their set of six possible weights $\{-3,-2,-1,1,2,3\}$. The equation used in this research (8) accordingly also is developed for six possible weights $\{-1,-0.66,-0.33,0.33,0.66,1\}$. It would not be applicable for sets with fewer or more elements. Future research is required to develop generally applicable metrics for comparison. For example, Markóczy and Goldberg [17] suggest an equation to determine the content difference between CMs by adding five additional parameters on the denominator and the modified the matrix distance for the numerator of the L\&W advanced equation (See p.134-135). It may also be applicable to FCM.

In the structural analysis of the FCM, this research did not calculate betweenness and closeness centralities, even though both are commonly used metrics for structure analysis [15], [24], [25]. However, as these metrics are used to determine the impact of concepts on information flows in a map, few research deal with these metrics for weighted and directed networks. Rubinov and Sporns [26] present closeness and betweenness centralities for the case of either directed or weighted networks, but not for weighted and directed networks such as FCM. In addition, some researchers recommend using 'measures of prestige' instead of 'measures of centralities' for directed networks [33], [35]. However, some researchers adopted betweenness and/or closeness centralities for FCM analysis [15], [31]. Therefore, further researches need to study which measures can determine the impact of concepts on the entire map properly.

Literature on structural analysis of networks also frequently proposes the use of an hierarchy index as a measure for checking the level of structural dominance [12], 
[32], [36]. Originally, this research followed the same path. However, when developing the illustration case above, the hierarchy index produced a value of over 1 , and thus outside of the acceptable range of $[0,1]$. After an in-depth review of the result and relevant literature, the author realized that the hierarchy index has originated from the investigating of the linearity of dominance in animal societies [28], [37], [38]. However, the structure of a FCM is different from the structure of animal societies in that a concept in an FCM can influence itself and concepts can impact each other. In addition, according to Shizuka and McDonald [28], Landau's hierarchy index is affected by the network size. In other words, if the size of the adjacency matrix increase, the hierarchy index decrease. Therefore, the author concludes that the hierarchy index is not appropriate for the structural analysis of FCMs.

\section{CONCLUSION}

In order to enable the investigation of cognitive differences between individuals and groups, this study reviews the literature on comparative analysis of $\mathrm{CM}$, social networks, and FCM and organizes the metrics in three categories according to their objectives: content, structure and dynamic behavior analyzes. It illustrates how these three types of metrics help to find differences among multiple FCMs and identify unique cognitions. Also, this research reveals some limitation in the comparative analysis of FCMs. In particular, content metrics are needed that are generalizable for all possible weights of causal relationships. Also, structural metrics that are suitable for directed and weighted FCMs still need to be developed. They may be conceptually similar to betweeneness and closeness centrality or build on the concept of "measures of prestige"

\section{REFERENCES}

[1] B. Kosko, "Fuzzy cognitive maps," Int. J. Man. Mach. Stud., vol. 24, no. 1, pp. 65-75, Jan. 1986.

[2] A. J. M. Jetter, "Fuzzy Cognitive Maps for Engineering and Technology Management: What Works in Practice?," in 2006 Technology Management for the Global Future - PICMET 2006 Conference, 2006, no. c, pp. 498-512.

[3] E. I. Papageorgiou, "Review study on fuzzy cognitive maps and their applications during the last decade," in 2011 IEEE International Conference on Fuzzy Systems (FUZZ-IEEE 2011), 2011, no. 1998, pp. $828-835$.

[4] A. K. Tsadiras, "Comparing the inference capabilities of binary, trivalent and sigmoid fuzzy cognitive maps," Inf. Sci. (Ny)., vol. 178, no. 20 , pp. $3880-3894,2008$.

[5] M. Amer, A. Jetter, and T. Daim, "Development of fuzzy cognitive map (FCM) based scenarios for wind energy," Int. J. Energy Sect. Manag., vol. 5, no. 4, pp. 564-584, Nov. 2011.

[6] R. Sperry and A. J. Jetter, "Fuzzy Cognitive Maps to Implement Corporate Social Responsibility in Product Planning: A Novel Approach," 2012 Proc. PICMET '12 Technol. Manag. Emerg. Technol., pp. 2536-2541, 2012.

[7] A. J. M. Jetter and R. C. Sperry, "Fuzzy Cognitive Maps for Product Planning: Using Stakeholder Knowledge to Achieve Corporate Responsibility," 2013 46th Hawaii Int. Conf. Syst. Sci., pp. 925-934, Jan. 2013
[8] B. S. Yoon and A. J. Jetter, "Investigation of Different Perspectives between Developers and Customers: Robotic Vacuum Cleaners," in Proceedings of PICMET '14 Conference: Portland International Center for Management of Engineering and Technology; Infrastructure and Service Integration, 2014, pp. 2307-2313.

[9] A. J. Jetter and K. Kok, "Fuzzy Cognitive Maps for futures studies-A methodological assessment of concepts and methods," Futures, vol. 61, pp. 45-57, Sep. 2014.

[10] C. Eden, F. Ackermann, and S. Cropper, "the Analysis of Cause Maps," J. Manag. Stud., vol. 29, no. 3, pp. 309-324, May 1992.

[11] C. Eden, "Analyzing cognitive maps to help structure issues or problems," Eur. J. Oper. Res., vol. 159, no. 3, pp. 673-686, Dec. 2004.

[12] U. Özesmi and S. L. Özesmi, "Ecological models based on people's knowledge: a multi-step fuzzy cognitive mapping approach," Ecol. Modell., vol. 176, no. 1-2, pp. 43-64, Aug. 2004.

[13] T. J. Septer, J. Dijkstra, and F. N. Stokman, "Detecting and measuring crucial differences between cognitive maps," Ration. Soc., vol. 24, no. 4, pp. 383-407, 2012.

[14] S. Wang, "A Dynamic Perspective of Differences Between Cognitive Maps,” J. Oper. Res. Soc., vol. 47, no. 4, pp. 538-549, 1996.

[15] M. Obiedat, S. Samarasinghe, and G. Strickert, "A New Method for Identifying the Central Nodes in Fuzzy Cognitive Maps using Consensus Centrality Measure," in 19th International Congress on Modelling and Simulation, 2011, no. December, pp. 1084-1091.

[16] R. Axelrod, Structure of Decision. The Cognitive Maps of Political Elites. Prinseton: Princeton University Press, 1976.

[17] L. Markóczy and J. Goldberg, "A Method for Eliciting and Comparing Causal Maps," J. Manage., vol. 21, no. 2, pp. 305-333, Apr. 1995.

[18] I. Clarke and W. Mackaness, "Management intuition: an interpretative account of structure and content using cognitive maps.," no. March, 2001.

[19] D. P. Tegarden and S. D. Sheetz, "Group cognitive mapping: A methodology and system for capturing and evaluating managerial and organizational cognition," Omega, vol. 31, no. 2, pp. 113-125, 2003.

[20] G. P. Hodgkinson, a. J. Maule, and N. J. Bown, "Causal Cognitive Mapping in the Organizational Strategy Field: A Comparison of Alternative Elicitation Procedures," Organ. Res. Methods, vol. 7, no. 1, pp. 3-26, 2004.

[21] K. Langfield-Smith and A. Wirth, "Measuring Differences between Cognitive Maps," J. Oper. Res. Soc., vol. 43, no. 12, p. 1135, Dec. 1992.

[22] B. Kosko, "Hidden patterns in combined and adaptive knowledge networks," Int. J. Approx. Reason., vol. 2, no. 4, pp. 377-393, Oct. 1988.

[23] P. Bonacich and P. Lloyd, "Eigenvector-like measures of centrality for asymmetric relations," Soc. Networks, vol. 23, no. 3, pp. 191-201, 2001

[24] A. Barrat, M. Barthélemy, R. Pastor-Satorras, and A. Vespignani, "The architecture of complex weighted networks.," Proc. Natl. Acad. Sci. U. S. A., vol. 101, no. 11, pp. 3747-3752, 2004.

[25] M. E. J. Newman, "Analysis of weighted networks," Phys. Rev. E Stat. Nonlinear, Soft Matter Phys., vol. 70, no. 5 2, pp. 1-9, 2004.

[26] M. Rubinov and O. Sporns, "Complex network measures of brain connectivity: uses and interpretations.," Neuroimage, vol. 52, no. 3, pp. 1059-69, 2010.

[27] B. Corominas-Murtra, J. Goni, C. Rodríguez-Caso, and R. Solé, "Hierarchy and information in feedforward networks," ArXiv eprints, 2010.

[28] D. Shizuka and D. B. McDonald, "A social network perspective on measurements of dominance hierarchies," Anim. Behav., vol. 83, no. 4, pp. 925-934, 2012.

[29] F. M. Vanwindekens, P. V. Baret, and D. Stilmant, "A new approach for comparing and categorizing farmers' systems of practice based on cognitive mapping and graph theory indicators," Ecol. Modell., vol. 274, pp. 1-11, 2014.

[30] L. C. Freeman, S. P. Borgatti, and D. R. White, "Centrality in valued graphs: A measure of betweeness based on network flow," Soc. Networks, vol. 12, pp. 141-154, 1991.

[31] V. K. Mago, H. K. Morden, C. Fritz, T. Wu, S. Namazi, P. Geranmayeh, R. Chattopadhyay, and V. Dabbaghian, "Analyzing the 
impact of social factors on homelessness: a fuzzy cognitive map approach.," BMC Med. Inform. Decis. Mak., vol. 13, p. 94, 2013.

[32] S. a Gray, E. Zanre, and S. R. J. Gray, "Fuzzy Cognitive Maps as Representations of Mental Models and Group Beliefs," Fuzzy Cogn. Maps Appl. Sci. Eng. SE - 2, vol. 54, pp. 29-48, 2014.

[33] S. Wasserman and K. Faust, Social Network Analysis: Methods and Application, 1st ed. New York, NY: Cambridge University Press, 1994.

[34] J. A. Dickerson and B. Kosko, "Virtual Worlds as Fuzzy Cognitive Maps," Presence Teleoperators Virtual Environ., vol. 3, no. 2, pp. 173189, Jan. 1994.

[35] W. de Nooy, A. Mrvar, and V. Batagelj, Exploratory Social Network
Analysis with Pajek, 2nd ed. New York, NY: Cambridge University Press, 2011.

[36] O. Roban and G. Secme, "Prediction of socio-economical consequences of privatization at the firm level with fuzzy cognitive mapping," Inf. Sci. (Ny)., vol. 169, no. 1-2, pp. 131-154, Jan. 2005.

[37] H. G. Landau, "On dominance relations and the structure of animal societies: I. Effect of inherent characteristics," Bull. Math. Biophys., vol. 13, no. 1, pp. 1-19, Mar. 1951

[38] H. Devries, "An improved test of linearity in dominance hierarchies containing unknown or tied relationships," Anim. Behav., vol. 50, no. 5, pp. 1375-1389, 1995.

\section{APPENDIX I}

To calculate the numerator of the equation (8), matrix distance, a distance matrix is formed from the adjacency matrices of both maps like below Figure 8;

$$
D R(A, B)=\frac{\sum_{i=1}^{p} \sum_{j=1}^{p} \mid \operatorname{sgn}\left(a_{i j}\right)-\operatorname{sgn}\left(b_{i j} \mid\right.}{2 p c^{2}+2 p c\left(p u_{A}+p u_{B}\right)+p u_{A}^{2}+p u_{B}^{2}-\left(2 p c+p u_{A}+p u_{B}\right)}
$$

\begin{tabular}{|r|r|r|r|r|r|r|r|r|r|r|r|r|r|r|r|r|r|r|r|r|}
\hline & 1 & 2 & 3 & 4 & 5 & 6 & 7 & 8 & 9 & 10 & 11 & 12 & 13 & 14 & 15 & 16 & 17 & 23 & 24 & 25 \\
\hline 1 & 0 & 0 & 0 & 0 & 0 & 0 & 0 & 0 & 0 & 0 & 0 & 0 & 0 & 0 & 0 & 0 & 0 & 0 & 0 & 1 \\
\hline 2 & 0 & 0 & 1 & 1 & 0 & 0 & 0 & 0 & 0 & 0 & 0 & 0 & 0 & 0 & 1 & 0 & 0 & 0 & 0 & 0 \\
\hline 3 & 0 & 0 & 0 & 0 & 0 & 0 & 0 & 0 & 0 & 0 & 0 & 0 & 0 & 0 & 0 & 0 & 0 & 1 & 0 & 0 \\
\hline 4 & 0 & 0 & 0 & 0 & 0 & 0 & 0 & 0 & 0 & 0 & 0 & 0 & 0 & 0 & 0 & 0 & 0 & 1 & 0 & 0 \\
\hline 5 & 0 & 0 & 0 & 0 & 0 & 0 & 0 & 0 & 0 & 0 & 0 & 0 & 0 & 0 & 0 & 0 & 0 & 0 & 0 & 0 \\
\hline 6 & 0 & 0 & 0 & 0 & 0 & 0 & 0 & 0 & 0 & 0 & 0 & 0 & 0 & 0 & 1 & 0 & 0 & 0 & 0 & 0 \\
\hline 7 & 1 & 1 & 0 & 0 & 0 & 0 & 0 & 0 & 0 & 0 & 0 & 0 & 0 & 0 & 0 & 0 & 0 & 0 & 0 & 0 \\
\hline 8 & 0 & 0 & 0 & 0 & 0 & 0 & 0 & 0 & 1 & 1 & 0 & 0 & 0 & 0 & 0 & 0 & 0 & 0 & 0 & 0 \\
\hline 9 & 0 & 0 & 0 & 0 & 0 & 0 & 0 & 0 & 0 & 0 & 0 & 0 & 0 & 0 & 0 & 0 & 0 & 0 & 0 & 0 \\
\hline 10 & 0 & 0 & 0 & 0 & 0 & 0 & 1 & 0 & 0 & 0 & 1 & 0 & 0 & 0 & 0 & 0 & 0 & 0 & 0 & 0 \\
\hline 11 & 0 & 0 & 0 & 0 & 0 & 0 & 0 & 0 & 0 & 0 & 0 & 0 & 1 & 0 & 0 & 0 & 0 & 0 & 0 & 0 \\
\hline 12 & 0 & 0 & 0 & 0 & 0 & 0 & 1 & 0 & 0 & 0 & 0 & 0 & 0 & 0 & 0 & 0 & 1 & 0 & 0 & 0 \\
\hline 13 & 0 & 0 & 0 & 0 & 0 & 0 & 0 & 0 & 0 & 0 & 0 & 0 & 0 & 1 & 0 & 0 & 0 & 0 & 0 & 0 \\
\hline 14 & 0 & 0 & 0 & 0 & 0 & 0 & 0 & 0 & 0 & 0 & 0 & 0 & 0 & 0 & 0 & 0 & 0 & 0 & 0 & 0 \\
\hline 15 & 0 & 0 & 0 & 0 & 0 & 0 & 0 & 0 & 0 & 0 & 0 & 0 & 0 & 0 & 0 & 0 & 0 & 0 & 0 & 0 \\
\hline 16 & 0 & 0 & 0 & 0 & 0 & 0 & 0 & 0 & 0 & 0 & 0 & 0 & 0 & 0 & 0 & 0 & 0 & 0 & 0 & 0 \\
\hline 17 & 1 & 0 & 1 & 0 & 0 & 0 & 0 & 0 & 0 & 0 & 0 & 0 & 0 & 0 & 0 & 0 & 0 & 0 & 0 & 0 \\
\hline 23 & 0 & 0 & 0 & 0 & 0 & 0 & 0 & 0 & 0 & 0 & 0 & 0 & 0 & 0 & 0 & 0 & 0 & 0 & 1 & 0 \\
\hline 24 & 0 & 0 & 0 & 1 & 0 & 0 & 0 & 0 & 0 & 0 & 0 & 0 & 0 & 0 & 0 & 0 & 0 & 0 & 0 & 0 \\
\hline 25 & 0 & 0 & 0 & 0 & 0 & 0 & 0 & 0 & 0 & 0 & 0 & 0 & 0 & 0 & 1 & 0 & 0 & 0 & 0 & 0 \\
\hline
\end{tabular}

Figure 8. The distance matrix of the FCM 1and the FCM 2

The blue colored area of above matrix means that these five elements (concept number 2, 7, 8, 11 and 13) are included in only the adjacency matrix of the FCM1, not of the FCM2 while the gray colored area means vice versa. Therefore, the number of unique elements in the FCM 1, puA, is 5, while the number of unique elements in the FCM 2, puB, is 4 . The value of matrix distance calculated with the numerator of Equation (8) is 22. The number of elements common to both maps, pc, is 11 . As a result, the distance ratio, Equation (8), is equal to 0.049. 